\title{
RELIGIUSITAS MAHASISWA PERBANKAN SYARIAH S1 UIN MALANG YANG MENGGUNAKAN JASA BANK SYARIAH
}

\author{
Mohammad Dendi Abdul Nasir \\ Universitas Islam Negeri Sunan Kalijaga Yogyakarta, dendinasir8@gmail.com
}

\begin{abstract}
Religiousity is an expression of embraced system of trust that feels its values, so it created an option to react and behave in decision making. Islamic bank is a bank implements Islamic values which are arranged in Fatwa Dewan Syariah Nasional. In Islamic banking world, religiousity is one of many factors for customers to choose Islamic bank to save their money on. This research aims to discover how much is religiosity of students which are also costumers of Islamic bank. This is a qualitative research. Subjects for this research are 5 students as key informants and 10 students as main informants. This research uses primary and secondary data. Primary data is taken from interview with subjects and secondary data taken from older researches and theory books. The analysis of the dimension of religiosity illustrates to us that the dimension of religiosity has an effect on students both before becoming a customer, when becoming a customer, and the long-term effect.
\end{abstract}

Keyword: Religiousity, Students, Islamic Bank 


\begin{abstract}
ABSTRAK
Religiusitas merupakan ekspresi atau perwujudan dari sistem kepercayaan yang dianut dengan menghayati nilai-nilainya secara substansi sehingga melahirkan pilihan sikap dan perilaku dalam mengambil keputusan. Bank syariah merupakan bank yang dalam pelaksanaannya menerapkan nilai-nilai islam yang telah diatur dalam Fatwa Dewan Syariah Nasional. Dalam dunia perbankan syariah, religiusitas adalah salah satu faktor nasabah untuk menabung. Penelitian ini bertujuan untuk mengetahui seberapa jauh religiusitas mahasiswa dalam menggunakan jasa bank syariah. Jenis penelitian ini adalah penelitian kualitatif. Adapun subjek dalam penelitian ini berjumlah 5 mahasiswa sebagai key informan dan 10 mahasiswa sebagai informan utama. Jenis data yang dipakai pada penelitian ini adalah data primer dan data sekunder. Data primer diambil dari wawancara dengan subyek penelitian, sedangkan data sekunder diambil dari penelitian terdahulu dan buku penunjang teori. Analisis mengenai dimensi religiusitas menggambarkan kepada kita bahwa dimensi religiusitas memberikan efek terhadap mahasiswa baik itu sebelum menjadi nasabah, ketika menjadi nasabah, maupun efek jangka panjang.
\end{abstract}

Kata Kunci: Religiusitas, Mahasiswa, Bank Syariah 


\section{PENDAHULUAN}

Ekonomi adalah salah satu sektor muamalah yang mendapat perhatian besar dalam Islam, sehingga para cendikiawan muslim sepanjang zaman berusaha mengembangkan teknik penerapan prinsip-prinsip syariah dalam aktivitas ekonomi, termasuk di dalamnya sektor perbankan syariah. Salah satu ciri khas bank Islam yang tidak ada pada bank konvensional adalah tidak adanya bunga dalam kegiatan operasionalnya. Dalam pandangan Islam bunga pinjaman uang, modal baik untuk tujuan produktif maupun konsumtif, dengan tingkat tinggi maupun rendah, dan dalam jangka waktu panjang maupun pendek adalah termasuk riba (Saefuddin, 2011: 145).

Merespon kajian ulama terhadap bunga bank, praktik perbankan Islam di Indonesia dimulai pada akhir 1980-an yang dimulai dengan lahirnya bank syariah pertama di Indonesia yaitu Bank Muamalat pada tahun 1992. Beberapa saat setelah berdirinya bank syariah di Indonesia kondisi keuangan syariah di Indonesia berjalan lambat. Namun krisis ekonomi tahun 1997 membawa keuntungan tersendiri bagi perbankan syariah di Indonesia. Disaat bank konvensional mengalami negative spread, bank Muamalat mampu bertahan terhadap krisis tersebut. Fakta bertahannya bank syariah dari badai moneter itu mendorong sejumlah pihak melirik dan tertarik untuk mendirikan atau membuka bank bersistem syariah (Saefuddin, 2011: 226).

Sangat penting bagi bank untuk menciptakan strategi tersendiri agar dapat menguasai pasar dan memenangkan persaingan, salah satunya adalah dengan mengetahui perilaku konsumen (nasabah). Namun dalam praktiknya, mengetahui perilaku konsumen dan menganalisis setiap pengambilan keputusan yang dilakukan oleh konsumen tidaklah mudah. Banyak faktor yang mempengaruhinya antara lain faktor internal yang berasal dari nasabah itu sendiri dan faktor eksteral yaitu berupa rangsangan yang dilakukan oleh pihak bank dan lingkungan sekitar bank (Karmila, 2013: 2). Selain faktor-faktor tersebut, Sumarwan (2011: 200) menyatakan bahwa agama merupakan faktor pembentuk perilaku pembelian bagi konsumen di Indonesia.

Pengertian religiusitas menurut Glock dan Stark (1968) adalah seberapa jauh pengetahuan, seberapa kokoh keyakinan, seberapa tekun pelaksanaan ibadah dan seberapa dalam penghayatan agama yang dianut seseorang. Glock dan Stark (1968) menganalisis religiusitas ke dalam lima dimensi, yaitu: dimensi ideologis, ritualistik, eksperensial, intelektual, dan konsekuensi.

Penelitian yang dilakukan oleh Muchlis (2011: 32) tentang persepsi dan sikap masyarakat Jawa Tengah terhadap bank syariah menghasilkan salah satu kesimpulan bahwa faktor agama adalah motivator terpenting untuk mendorong penggunaan jasa bank syariah. Menurut penelitian yang dilakukan Woldie dan Nasser pada tahun 2003 di Qatar tentang "Islamic Banking in The West: The Need for Islamic Banking in The UK" dalam Wibowo (2007: 11), terungkap faktor-faktor alasan pelanggan bermitra dengan bank syari'ah. Setelah dirangking maka urutan motivasi bermitra dengan bank syari'ah adalah pertama faktor relegiusitas (keagamaan), kedua kepercayaan terhadap terhadap komite pengawasan dalam 
bank syari'ah, ketiga kerahasiaan, keempat reputasi dan citra dan kelima sifat sosial dan ramah dari pegawai bank.

Kelompok usia muda yang diisi oleh kalangan mahasiswa merupakan alasan pemilihan objek penelitian ini. Secara khusus, peneliti tertarik untuk mengkaji lebih dalam di Jurusan Perbankan Syariah S1 Fakultas Ekonomi UIN Maulana Malik Ibrahim Malang. Latar belakang ilmu perbankan syariah dan ilmu ekonomi islam menjadi faktor yang unik untuk dikaji.

\section{LITERATUR REVIEW \\ Religiusitas}

Religiusitas dalam konteks keimanan adalah sesuatu yang sifatnya subyektif. Tingkat keimanan seseorang menurut Islam secara pasti hanya Allah saja yang mengetahui. Namun, setidaknya pernyataan seseorang tentang pengalaman religiusitasnya dapat dijadikan referensi pijakan awal dari pengukuran tingkat religiusitas (Wibowo, 2007: 12). Glock dan Stark (1968) menyatakan bahwa terdapat lima aspek atau dimensi dari religiusitas yaitu:

1. Dimensi Ideologis

Dimensi idiologis atau keyakinan dapat diartikan seberapa tingkat keyakinan seseorang terhadap kebenaran ajaran agamanya, terutama terhadap ajaran-ajaran yang fundamental atau bersifat dogmatis. Dalam Islam, isi dari dimensi keyakinan adalah menyangkut keyakinan tentang adanya Allah, Malaikat, Rasul/Nabi, kitab Allah, surga, neraka, qodho dan qodar.

2. Dimensi Ritualistik

Dimensi ritualistik atau praktik dapat diartikan dengan seberapa tingkat kepatuhan seseorang dalam mengerjakan kegiatan-kegiatan ritual sebagaimana diperintahkan atau dianjurkan oleh agama yang dianutnya.

3. Dimensi Eksperensial

Dimensi eksperiensial atau pengalaman dapat diartikan seberapa tingkat seseorang dalam merasakan dan mengalami perasaan-perasaan dan pengalaman religius.

4. Dimensi Intelektual

Dimensi intelektual atau pengetahuan dapat diartikan dengan seberapa tingkat pengetahuan dan pemahaman seseorang terhadap ajaran agamanya, terutama mengenai ajaran pokok sebagaimana termuat dalam kitab sucinya.

5. Dimensi Konsekuensi

Dimensi konsekuensi atau pengamalan berkenaan dengan seberapa tingkat seseorang dalam berperilaku yang dimotivasi oleh ajaran agamanya. Perilaku tersebut adalah perilaku individu yang berhubungan dengan dunianya. 


\section{Bank Syariah Dan Tujuannya}

Secara bahasa dalam pengertian bank secara umum, kata Bank berasal dari kata Banque dalam bahasa Perancis dan Branco dalam bahasa Italia yang berati peti atau almari. Kata itu menyiratkan makna bahwa Banque atau Branco sebagai tempat penyimpanan bendabenda berharga seperti peti berlian, peti uang, dan sebagainya. Selebihnya bank diartikan sebagai sesuatu yang mempunyai unsur-unsur seperti struktur, manajemen, fungsi hak dan kewajiban (Sudarsoni, 2004: 27).

Bank Syariah adalah bank yang beroperasi dengan tidak mengandalkan pada bunga. Bank Syariah juga dapat diartikan sebagai lembaga keuangan atau perbankan yang operasional dan produknya dikembangkan berlandaskan Al-Qur'an dan Hadist Nabi SAW. Atau dengan kata lain, Bank Syariah adalah lembaga keuangan yang usaha pokoknya memberikan pembiayaan dan jasa-jasa lainnya dalam lalu lintas pembayaran serta peredaran uang yang pengoperasiannya disesuaikan dengan prinsip-prinsip syariat Islam (Muhammad, 2005: 13).

Hadirnya bank syariah memiliki peran yang sangat penting sebagai sarana mewujudkan tujuan dari sistem sosial dan ekonomi Islam. Tujuan diharapkan dari sistem perbankan syariah menurut Chapra (2002: 2) adalah sebagai berikut:

1. Kemakmuran ekonomi yang meluas dengan tingkat kerja yang penuh dan tingkat pertumbuhan ekonomi yang optimum.

2. Keadilan sosial-ekonomi dan distribusi pendapatan dan kekayaan yang merata.

3. Stabilitas nilai uang untuk memungkinkan alat tukar tersebut menjadi suatu unit perhitungan yang terpercaya, standar pembayaran yang adil dan nilai simpan yang stabil.

4. Mobilisasi dan investasi tabungan bagi pembangunan ekonomi dengan cara-cara tertentu yang menjamin bahwa pihak-pihak yang berkepentingan mendapatkan bagian pengembalian yang adil.

5. Pelayanan efektif atas semua jasa-jasa yang biasanya diharapkan dari system perbankan

\section{METODE}

Dalam penelitian ini pendekatan yang dilakukan adalah melalui pendekatan kualitatif. Artinya data yang dikumpulkan bukan berupa angka-angka, melainkan data tersebur berasal dari naskah wawancara, catatan lapangan, dokumen pribadi, catatan, memo, dan dokumen resmi lainnya. Sehingga yang menjadi tujuan dari penelitian kualitatif ini adalah ingin menggambarkan realita empiris dibalik fenomena secara mendalam, rinci dan tuntas. Oleh karena itu penggunaan pendekatan kualitatif dalam penelitian ini adalah dengan mencocokkan antara realita empiris dengan teori yang berlaku dengan menggunakan metode deskriptif (Moleong, 2009: 131). Lokasi dalam penelitian ini dilakukan di Jurusan Perbankan Syariah S1 Fakultas Ekonomi Universitas Islam Negeri Maulana Malik Ibrahim Malang yang beralamatkan di Jalan Gajayana No.50 Malang.

Kriteria subjek penelitian atau informan dalam penelitian ini adalah (i) Mahasiswa Jurusan Perbankan Syariah S1 Fakultas Ekonomi UIN Maulana Malik Ibrahim Malang (ii) Mahasiswa yang aktif menggunakan jasa bank syariah (iii) Mahasiswa yang sudah 
menyelesaikan semua mata kuliah, tidak termasuk mata kuliah skripsi dan (iv) Mahasiswa yang memiliki prestasi atau pengalaman besar di bidang Ekonomi Islam atau Perbankan Syariah.

Jenis data dalam penelitian ini adalah data primer dan data sekunder. Data primer adalah data yang diperoleh dari proses wawancara dengan mahasiswa tingkat akhir Perbankan Syariah S1 yang menggunakan jasa bank Syariah berjumlah 5 mahasiswa sebagai key informan dan 10 mahasiswa sebagai informan utama. Data sekunder adalah data yang diperoleh dari media online dan publikasi penelitian kepustakaan. Teknik pengumpulan data yang dilakukan adalah wawancara, observasi, tinjauan literature, dokumentasi.

Analisis data yang dilakukan dalam penelitian ini adalah reduksi data, penyajian data dan penarikan kesimpulan (Sutopo dan Andrianus, 2010). Reduksi data adalah dengan memfokuskan pada hal-hal yang penting, dicari tema dan polanya. Penyajian data adalah dengan uraian singkat, bagan, hubungan antar kategori, dan sejenisnya. Sehingga dapat diperoleh kesimpulan sesuai dengan fokus penelitian.

\section{PEMBAHASAN}

Religiusitas merupakan bentuk aspek religi yang telah dihayati oleh setiap individu dalam hati. Makna religiusitas yang digambarkan dalam beberapa dimensi yang harus dipenuhi sebagai petunjuk bagaimana cara menjalankan hidup dengan benar, agar setiap individu tersebut mencapai kebahagiaan, ketenangan, dan keselamatan baik di dunia maupun di akhirat.

Dalam pembahasan kali ini akan mendeskripsikan tentang hasil analisis religiusitas mahasiswa Perbankan Syariah S1 UIN Maulana Malik Ibrahim Malang yang menggunakan jasa bank syariah sesuai pembagian dimensi menurut Glock dan Stark.

Berdasarkan hasil wawancara yang diperoleh dari semua informan yang berkenaan tentang dimensi-dimensi religiusitas adalah sebagai berikut:

- Dimensi yang pertama adalah dimensi ideologis. Keyakinan para mahasiswa yang menjadi informan dalam penelitian ini mengerucut pada konsep dan pelaksanaan. Para informan yang notabenenya mahasiswa jurusan perbankan syariah telah meyakini bahwa secara konseptual, bank syariah patuh terhadap fatwa-fatwa Dewan Syariah Nasional. Akan tetapi penerapannya di lapangan, bank syariah menyesuaikan kondisi lingkungan sekitar. Hal itu dibuktikan ketika melaksanakan Praktik Kerja Lapangan di Perbankan Syariah. Dalam penerapan prinsip syariahnya terhadap kegiatan perbankan, bank syariah belum mampu menerapkan secara keseluruhan. Hal itu yang membuat mahasiswa mempunyai keraguan terhadap pelaksanaan bank syariah yang belum benar-benar berjalan sesuai konsep sampai saat ini.

- Dimensi yang kedua adalah dimensi ritualistik. Mahasiswa Perbankan Syariah S1 UIN Maulana Malik Ibrahim Malang hanya menggunakan produk tabungan saja karena kebutuhan selama masa studi. Kemudian selain hanya dengan menggunakan produk tabungan saja, mahasiswa belum bisa menggunakan produk-produk yang lain seperti 
pembiayaan. Seperti yang diketahui, nasabah harus melaksanakan sesuai prosedur dan memenuhi persyaratan pengajuan pembiayaan. Sebagai contoh persyaratan pembiayaan Bank BNI Syariah bahwa nasabah harus memiliki penghasilan tetap, mempunyai jaminan yang sesuai. Kemudian mahasiswa masih terlalu sulit untuk berhenti menjadi nasabah bank konvensional, atau dalam kata lain hanya menjadi nasabah bank syariah, dikarenakan fasilitas-fasilitas yang diberikan bank syariah kepada nasabah masih belum maksimal.

- Dimensi yang ketiga adalah dimensi eksperensial. Hal yang membedakan transaksi di bank syariah dan bank konvensional adalah bank syariah tidak memberlakukan bunga, melainkan prinsip bagi hasil. Bagi umat muslim, prinsip bagi hasil merupakan solusi untuk keluar dari system riba yang itu tidak diperbolehkan dalam syariat islam. Hal itu yang membuat mahasiswa Perbankan Syariah S1 UIN Maulana Malik Ibrahim Malang merasa tenang, aman dan nyaman selama menggunakan jasa bank syariah. Selain itu, mahasiswa Perbankan Syariah S1 UIN Maulana Malik Ibrahim Malang sudah merasakan pelayanan yang memuaskan, baik itu di kantor maupun ketika bertransaksi di mesin ATM bank syariah, akan tetapi ada beberapa keluhan diantaranya adalah sulitnya mengakses fasilitasfasilitas bank syariah di daerah. Kebanyakan kantor maupun ATM bank syariah tersebar di kota. Disisi lain, bank syariah mempunyai pengaruh terhadap mahasiswa Perbankan Syariah S1 UIN Maulana Malik Ibrahim Malang diantaranya mendorong mereka bergerak dalam kegiatan perekonomian yang sesuai dengan prinsip-prinsip syariah.

- Dimensi yang keempat adalah dimensi intelektual. Pengetahuan mahasiswa tentang ilmu perbankan syariah maupun tentang produk-produk, akad-akad, maupun konsep bisnis bank syariah tidak diragukan lagi. Pengetahuan mahasiswa tersebut mempengaruhi keaktifannya menjadi nasabah bank syariah. Selain itu, mereka sudah belajar selama 7 semester lebih di jurusan Perbankan Syariah S1 UIN Maulana Malik Ibrahim Malang yang sesuai dengan kompetensi lulusan yang diharapkan oleh jurusan.

- Dimensi yang terakhir adalah dimensi konsekuensi. Mahasiswa jurusan Perbankan Syariah S1 UIN Maulana Malik Ibrahim Malang mempunyai komitmen tinggi dan tantangan terhadap berkembangnya bank syariah kedepan. Komitmen dan tantangan yang pertama adalah mahasiswa ingin menjadi pionir-pionir praktik ekonomi islam dan perbankan syariah. Misalnya mahasiswa mengelola keuangan halal tanpa riba, dan berbisnis sesuai syariah. Komitmen dan tantangan yang kedua adalah mahasiswa ingin mengedukasi masyarakat agar pemahamannya tentang ekonomi islam dan perbankan syariah bisa meningkat. Sebagai insan yang berpendidikan, mahasiswa secara relatif lebih cepat memahami dan memiliki akses kebaikan ekonomi islam daripada masyarakat lain. Hal itu bisa mendorong praktik ekonomi islam dan perbankan syariah juga meningkat di tengahtengah masyarakat. 


\section{SIMPULAN}

Analisis mengenai dimensi religiusitas diatas menggambarkan kepada kita bahwa dimensi religiusitas memberikan efek atau pengaruh terhadap mahasiswa baik itu sebelum menjadi nasabah, ketika menjadi nasabah, dan efek jangka panjang.

Mahasiswa Jurusan Perbankan Syariah S1 Fakultas Ekonomi UIN Maulana Malik Ibrahim Malang meyakini bahwa bank syariah secara konseptual telah sesuai dengan prinsip syariah karena telah diatur dalam Fatwa Dewan Syariah Nasional. Sedangkan secara implementasi, mereka belum bisa meyakini bahwa bank syariah itu sudah menerapkan prinsip syariah.

Dalam menggunakan jasa bank syariah, mereka hanya memakai produk tabungan saja, dikarenakan kebutuhan mahasiswa masih menabung dan menyimpan uang saja. Mereka juga sudah merasakan pelayanan yang memuaskan, baik itu di kantor maupun ketika bertransaksi di mesin ATM bank syariah, akan tetapi ada beberapa keluhan diantaranya adalah sulitnya mengakses fasilitas-fasilitas bank syariah di daerah. Mereka juga mempunyai pengetahuan yang baik, Hal itu dibuktikan dengan studi selama 7 semester lebih, serta melaksanakan Praktik Kerja Lapangan di lembaga perbankan syariah. Mereka juga mempunyai 2 komitmen dan tantangan kedepannya. Yang pertama adalah dengan menjadi pionir-pionir praktik ekonomi islam dan perbankan syariah. Kemudian yang kedua adalah menjadi edukator bagi masyarakat, agar pemahaman masyarakat tentang ekonomi islam dan perbankan syariah bisa meningkat.

Kemudian ada beberapa hal yang diharapkan oleh peneliti. Hal yang pertama adalah mahasiswa diharapkan terus menyebarluaskan informasi dan edukasi kepada masyarakat mengenai pelarangan riba, yang tidak hanya terbatas pada praktek-praktek perbankan, tetapi juga pada dalam kehidupan sehari-hari. Hal yang kedua adalah instansi pendidikan diharapkan terus melaksanakan program-program yang bisa meningkatkan pengetahuan dan pengalaman mahasiswa. Harapan yang terakhir, bank syariah diharapkan lebih intens mensosialisasikan produknya, dan menghilangkan image bunga bank.

\section{REFERENSI}

Chapra, M. Umer. 2000. Sistem Moneter Islam: Edisi terjemah. Jakarta: Gema Insani Press \& Tazkia.

Glock, Charles., Stark, Rodney. 1968. American Piety: The Nature of Religious Commitment. University of California Press.

Karmila, Yaumi Nurjanah. 2013. Pengaruh Pelayanan Terhadap Keputusan Nasabah Dalam Menggunakan Produk Tabungan Pada PT. BNI Syariah Surabaya. Skripsi. Surabaya: UIN Sunan Ampel Surabaya. 
Muchlis. 2011. Perilaku Menabung di Perbankan Syariah Jawa Tengah. Disertasi. Semarang: Universitas Diponegoro Semarang.

Muhammad. 2005. Manajemen Bank Syariah. Yogyakarta: UPP AMPYKPN.

Moleong, Lexy. 2009. Metode Penelitian Kualitatif. Bandung: Remaja Rosda Karya.

Saefuddin, AM. 2011. Membumikan Ekonomi Islam. Jakarta: PT PPA Consultants.

Sudarsoni, Heri. 2004. Bank \& Lembaga Keuangan Syariah. Yogyakarta: Ekonisia.

Sugiyono. 2013. Metode Penelitian Pendidikan Kuantitatif Kualitataif R\&D. Bandung: Alfabeta.

Sumarwan, Ujang. 2011. Perilaku Konsumen Teori Dan Penerapannya Dalam Pemasaran. Bogor: PT Ghalia Indonesia.

Sutopo, Ariesto Hadi dan Arief Adrianus. 2010. Terampil Mengolah Data Kualitatif. Jakarta: Prenada Media Group.

Wibowo, Ery AS. 2007. Faktor Relegiusitas Dalam Perbankan Syari'ah. Jurnal Fakultas Ekonomi Universitas Muhammadiyah Semarang. 